\title{
THE INFLUENCE OF MANAGEMENT COMMITMENT, LEADERSHIP, EMPLOYEE ENGAGEMENT, AND TRAINING ON SAFETY PERFORMANCE AT A MANUFACTURING INDUSTRY IN BATAM
}

\author{
Agustinus Setyawan ${ }^{1)}$, Ferdinand Nainggolan ${ }^{2)}$, Asnil Fauzi ${ }^{3)}$ \\ ${ }^{1,2,3)}$ Universitas Internasional Batam, Indonesia \\ Corresponding author: agustinus.setyawan@uib.ac.id
}

\begin{abstract}
This study is aimed to analyze the influence of management commitment, leadership, employee involvement, and training on safety performance. The samples were used by this study the employees who work in the manufacturing industry of Batam island. The method of data collection is conducted using a questionnaire distributed by google form to the companies. The sampling technique was used in this study is based on a sampling of purposive. The respondents are 138 questionnaires distributed to three electronics manufacturing companies in the Muka Kuning of Batam island. The study shows that employee involvement and training are considered significant a positive effect on safety performance. However, management commitment and leadership variables do not have a significant effect on safety performance.
\end{abstract}

Keywords: Management Commitment, Leadership, Employee Engagement, Training, Safety Performance

\section{Introduction}

The era of industrialization was marked by industrial centers that produced products and services in various parts of the world. One of the most critical industry types is the manufacturing industry which produces products on a large scale. These products are produced using work equipment, machines, production processes, chemicals, and labor using high technology assistance to ensure quality, quantity, and continuity are met. In addition to fulfilling aspects of quality, quantity, and continuity of products, the manufacturing industry is also encouraged to fulfill safety aspects in every work process and use of work equipment safely to prevent occupational accidents and occupational diseases. Losses due to work accidents can cause casualties, material losses for workers and victims' families, and hamper the overall production process.

The ILO data (2012) shows that more than 1.8 million deaths due to work occur every year in the Asia Pacific region. Meanwhile, the number of deaths due to work accidents is estimated to be even higher; namely, around 2.78 million people die each year. Approximately 374 million injuries and occupational diseases resulted in absences for treatment and recovery from these incidents. Meanwhile, data from the 2017 Employment Social Security Administration (ESSA) shows that the number of work accidents is around 123,041. And an increase in 2018, namely around 173,105 cases with claims for Work Accident Insurance (WAI) of Rp. 1.2 trillion.

Work safety has been a government concern for a long time. This is indicated by the issuance of Law no. 1 of 1970 concerning Work Safety. Based on the law, the definition of work safety is a protective measure aimed at ensuring that workers and other people in the workplace/company are always in a safe and healthy condition. Every source of production can be used safely and efficiently.

Several studies indicate that a high level of work accidents can be seen from the low level of safety performance. Among them is research conducted by Hong et al. in 2018 on the manufacturing industry in Malaysia and Cornelissen et al. in 2017 in the manufacturing industry in North Cyprus.

According to Hong et al. (2018), Safety performance can be measured from various factors, including management commitment, leadership, employee involvement, training, work climate, and safety culture. By managing these factors, companies can create a safe work environment to prevent work accidents. With the above background, research on the manufacturing industry in Batam city is needed on how much influence management commitment, leadership, employee involvement, and training have on work safety performance. So that this research can provide a reference for various parties such as the government and management in reducing the rate of work accidents in the manufacturing industry.

\section{Literature Review \\ Management Commitment}

Management commitment is the foundation of an effective safety management system. Zohar (1980) revealed that management commitment to safety is a significant factor affecting the effectiveness of internal control and contributing to the success of an organization's OH\&S management system. Management commitment is a visual element where employees can witness and feel what management shows when speaking to ensure safety in the workplace (Hofmann et al., 2013). 


\section{Leadership}

$\mathrm{Wu}(2005)$ defines leadership in terms of safety (safety leadership) as an interaction between leaders and employees, where leaders can exert their ability to influence followers to achieve organizational goals. According to Peter (2001), safety leadership is a sub-system of leadership in organizations where leadership quality significantly influences safety.

\section{Employee Engagement}

Employee engagement has been recognized as a behavior modification technique that involves communication and decision-making processes in an organization (Vinodkumar \& Bhasi, 2010). Vredenburgh (2002) further argues that employees closely related to work are the right personnel to promote workplace improvement through internal controls, risk assessment, and risk control. Punnett et al. (2013) emphasize that organizations must adopt employee involvement in safety activities such as inspections, accident investigations, workplace analysis, hazard prevention \& control, and training.

\section{Training}

According to Hong et al. (2018), safety-related training is a significant component of a safety management system. The training aims to increase awareness of potential hazards and risks and to help improve safety-related behaviors, attitudes, skills, and knowledge. In particular, O'Toole (2002) supports the concept that training functions to develop employee competencies to improve abilities, skills, and talents in terms of risk prevention. Therefore, Vinodkumar \& Bhasi (2010) emphasizes that safety training is an effective way to predict work accidents.

\section{Safety Performance}

Safety performance refers to "all individual actions or behaviors on the job to promote the health and safety of workers, clients, the public, and the environment" (Burke et al., 2002). Safety performance is considered an essential aspect of job performance in many industries and has been considered a tool for the direct prediction of occupational accidents and injuries (Griffin \& Neal, 2000). Safety performance is influenced by a complex number of factors. O'Dea \& Flin (2003) specifically describe four (4) factors that can affect safety performance: leadership, management commitment, employee involvement, and training.

\section{Hypotheses Development \\ Management Commitment}

According to (Hong et al., 2018), defining management commitment implies direct participation by the highest level management or top management in all critical and or critical aspects such as safety, quality, environment, security, etc., or organizational programs. Research examining the relationship between management commitment to safety performance has been investigated, among others, by Hong et al. (2018). Both groups of researchers revealed a significant positive effect between management commitment to safety performance.

\section{H1: Management commitment has a significant positive effect on safety performance.}

\section{Leadership}

Wu et al. (2008) define leadership as an interaction between leader and followers where the leader can exert influence on his followers to achieve safety goals in the company. Wu et al. (2008) also added that the different roles between leadership and management are often used interchangeably. The problem here is that many do not recognize the critical difference between these roles and their respective vital functions in building a strong safety performance. In particular, managers exist as part of the structural organizational hierarchy and exert formal influence on their subordinates. At the same time, leadership is a voluntary activity in which an individual exerts social influence on colleagues by providing examples of appropriate behavior to achieve common goals and produce positive changes in the organization. Of course, one individual can become both manager and leader, but this only happens through a conscious effort to perform both roles effectively. Research examining the relationship between safety leadership and safety performance has been investigated, among others, by Wu et al. (2008) and Wu et al. (2011). The two groups of researchers revealed a significant favorable influence between safety leadership on safety performance.

\section{H2: Leadership has a significant positive effect on safety performance.}

\section{Employee Engagement}

Hong (2018) defines employee engagement as direct employee participation to assist the company in achieving its vision and mission by applying ideas, expertise, and efforts to solve problems and make critical decisions. Several studies that have examined the relationship between employee involvement and safety performance include Ünal et al. (2019) and Hong et al. (2018). Ünal et al. (2019) conducted a study on workers in manufacturing companies in Turkey, showing a positive influence between employee work involvement and safety performance. The same results can be seen in the study conducted by Hong et al. 
(2018), where the work involvement of workers in the manufacturing industry in Malaysia has a positive influence on safety performance.

H3: Employee engagement has a significant positive effect on safety performance.

\section{Training}

Shang \& Lu, 2009 defines workplace training as a process that aims to improve the knowledge and skills of workers to do their jobs safely for them and their colleagues. Research examining the relationship between safety training and safety performance has been investigated, among others, by Endroyo et al., 2015; Shang \& Lu (2009), and Hong et al. (2018). The three groups of researchers revealed a significant positive effect between safety training on safety performance.

\section{H4: Training has a significant positive effect on safety performance.}

\section{Research Method}

This research is testing the hypothesis which explains phenomena in the form of relationships between variables. This research can be classified as primary research (basic, pure, fundamental research) related to solving theoretical problems based on the research objectives. This research is expected to contribute to theory development (Indriartoro \& Supomo, 2014).

The population in this study consists of production workers at three manufacturing companies in Batam with a total of 3000 people. The samples in this study consist of 138 production workers who worked at three manufacturing companies in Batam. This study uses a random sampling technique, using a questionnaire instrument. The method used is the Slovin method, and the data analysis used is SPPS.

\section{Result and Discussion}

Tabel 1. Partial Test of Solvability and Liquidity on Dividend Policy

\begin{tabular}{lccc}
\hline \multicolumn{1}{c}{ Variable } & Coefficient & t-Statistic & Prob. \\
\hline C & -17.61428 & -0.601909 & 0.5503 \\
\hline DER & 31.07002 & 4.838150 & 0.0000 \\
\hline CURRENT_RATIO & 0.091198 & 6.372556 & 0.0000 \\
\hline
\end{tabular}

Source: Output eviews 9.0 for windows

\section{Solvability Affects on Dividend Policy}

\section{Validity Test and Reliability Test}

Based on the results of the validity test, which shows the overall loading factor results, five variables fall into the valid criteria, namely management commitment (0.721), leadership (0.745), employee engagement (0.681), training (0.694), and safety performance (0.710).

The data processing reliability shows the Cronbach's alpha for the management commitment of 0.931 , leadership of 0.947 , employee engagement of 0.843 , training of 0.919 , and safety performance of 0.938 . These results show that all variables have composite reliability that is higher than 0.60 Hair et al. (2011).

\section{Hypothesis Testing}

Results of hypothesis testing in Table 1 show that $\mathrm{H} 1$ and $\mathrm{H} 2$ are not accepted with a probability value of $0.404(\mathrm{H} 1)$ and $0.227(\mathrm{H} 2)$, while $\mathrm{H} 3$ and $\mathrm{H} 4$ are accepted with a probability value of $0.007(\mathrm{H} 3)$ and 0.000 (H4).

Table 1. Hypotheses Testing

\begin{tabular}{lcl}
\hline \multicolumn{1}{c}{ Variable } & P-Values & Conclusion \\
\hline Management Commitment -> Safety Performance & 0,404 & H1 is not accepted \\
\hline Leadership -> Safety Performance & 0,227 & H2 is not accepted \\
\hline Employee Engagement -> Safety Performance & 0,007 & H3 is accepted \\
\hline Training -> Safety Performance & 0,000 & H4 is accepted \\
\hline
\end{tabular}

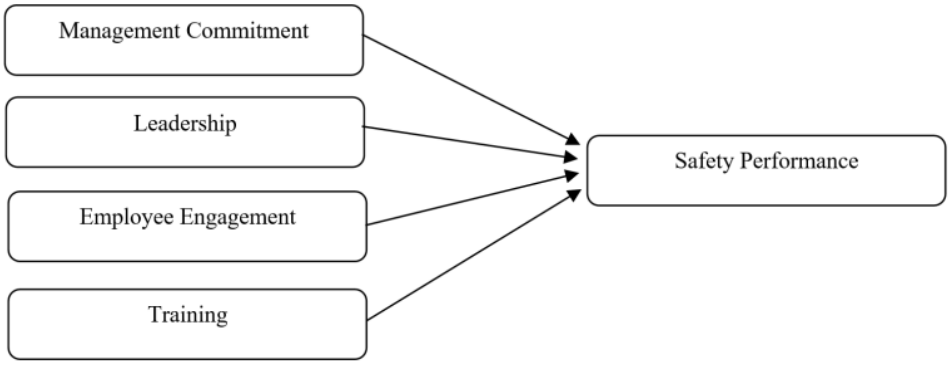

Figure 1. Research Model 
According to the result of the t-test, it is known that the management commitment variable has not a significant positive effect on safety performance in this study, as evidenced by a significance value of 0.404 . This result is consistent with previous research conducted by Nal et al. (2019). However, this is not consistent with the research conducted by Dursun (2011) and Lin \& Mills (2001). It can be concluded that the management commitment factor does not have a significant effect on safety performance because senior managers who work in manufacturing are generally more concerned with aspects of production and cost reduction (lean manufacturing) than safety aspects. After all, safety risks in manufacturing are lower than in the manufacturing industry. So it is difficult for them to understand the employee's need for safety. Management commitment becomes more effective when effective communication channels are established between senior managers and employees.

Based on the results of the t-test, it is known that the leadership variable has not a significant positive effect on safety performance in this study, as evidenced by a significance value of 0.227 . This is inconsistent with the research conducted by T. C. Wu et al. (2008), T. C. Wu et al. (2011), and Griffin \& Neal (2000). The leadership factor does not influence safety performance in the manufacturing industry. Perhaps this is due to the characteristics of the organization in the manufacturing industry that prioritizes mass production so that it places more emphasis on quality and quantity aspects than work safety aspects.

Based on the t-test results, it is known that employee engagement variable has a significant positive effect on safety performance in this study, as evidenced by a significance value of 0.007 . The results of this study are consistent with the research of nal et al. (2019), Fernández-Muñiz et al. (2007), Ali (2003), and Michael et al. (2005). Employee involvement at work plays an essential role in reducing workplace accidents due to its impact on employee motivation. If employees have a high level of involvement in safety programs, it will motivate them to work safely. Thus, employee involvement can improve safety performance within the company.

Based on the t-test results, it is known that training variable has a significant positive effect on safety performance in this study, as evidenced by a significance value of 0.000 . This is consistent with the research conducted by Endroyo et al. (2015), Shang et al. (2011), and Hong et al. (2018). The training factor has a positive influence on safety performance because training impacts changing employee attitudes and behavior. If the employee has safe behavior at work, he can prevent work accidents that may occur. So that training can improve safety performance in the company.

\section{Conclusion}

This study found that the main factors affecting safety performance are employee involvement and training factors. Meanwhile, management and leadership commitment factors have an insignificant influence on safety performance. Based on the study results, the training factor has a significant effect on safety performance because training impacts changing attitudes and behavior. If an employee has a safe attitude and behavior at work, he can automatically prevent work accidents that might occur. Training can also add insight and knowledge to employees regarding the safety risks associated with their work. So that training can improve safety performance in the company.

\section{References}

Ali, H. (2003). Management practice in safety culture and its influence on workplace injury An industrial study in Malaysia.

Bunner, J., Prem, R., \& Korunka, C. (2018). How to work intensification relates to organization-level safety performance: The mediating roles of safety climate, safety motivation, and safety knowledge. Frontiers in Psychology, 9(DEC), 1-13.

Burke, M. J., Sarpy, A. S., Tesluk, P. E., \& Smith-Crowe, K. (2002). General safety performance: A test of a grounded theoretical model. Personnel Psychology, 55(2), 429-457.

Cornelissen, P. A., Van Hoof, J. J., \& De Jong, M. D. T. (2017). Determinants of safety outcomes and performance: A systematic literature review of research in four high-risk industries. Journal of Safety Research, 62, 127-141.

Curcuruto, M., Conchie, S. M., Mariani, M. G., \& Violante, F. S. (2015). The role of prosocial and proactive safety behaviors in predicting safety performance. Safety Science, 80, 317-323.

Dea, A. O., \& Flin, R. (2003). Determining Workplace Safety Outcomes.

Dessler, G. (2013). Resource Management Thirteenth Edition.

Dursun, S. (2011). Güvenl i k kültürünün güvenl i k performansi üzer i ne etk i s i ne yönel i k b i r uygulama. June, 1-10.

Endroyo, B., Yuwono, B. E., Mardapi, D., \& Soenarto. (2015). Model of learning/training of Occupational Safety \& Health (OSH) based on the industrial construction industry. Procedia Engineering, 125, 83-88.

Fernández-Muñiz, B., Montes-Peón, J. M., \& Vázquez-Ordás, C. J. (2007). Safety culture: Analysis of the causal relationships between its key dimensions. Journal of Safety Research, 38(6), 627-641.

Griffin, M. A., \& Neal, A. (2000). Perceptions of safety at work: a framework for linking safety climate to safety performance, knowledge, and motivation. Journal of Occupational Health Psychology, 5(3), 347358 . 
Haworth, N., \& Hughes, S. (2012). The International Labour Organization. In Handbook of Institutional Approaches to International Business.

Hofmann, D. A., Jacobs, R., \& Landy, F. (2013). WITHDRAWN: Reprint of "High-Reliability Process Industries: Individual, Micro, and Macro Organizational Influences on Safety Performance." Journal of Safety Research, 26(3), 131-149.

Hong, C. C., Ramayah, T., \& Subramaniam, C. (2018). The relationship between critical success factors, internal control, and safety performance in the Malaysian manufacturing sector. Safety Science, 104(June 2016), 179-188.

Indriartoro, N., \& Supomo, B. (2014). Metodologi Penelitian Untuk Akuntansi Dan Manajemen (Edisi 1). In BPFE.

Lin, J., \& Mills, A. (2001). Measuring the occupational health and safety performance of construction companies in Australia. Facilities, 19, 131-139.

Makin, A. M., \& Winder, C. (2008). A new conceptual framework to improve the application of occupational health and safety management systems. Safety Science, 46(6), 935-948.

Michael, J. H., Evans, D. D., Jansen, K. J., \& Haight, J. M. (2005). Management commitment to safety as organizational support: Relationships with non-safety outcomes in wood manufacturing employees. Journal of Safety Research, 36(2), 171-179.

Mohamed, S. (1999). An empirical investigation of construction safety management activities and performance in Australia. Safety Science, 33(3), 129-142.

Mullen, J., Kelloway, E. K., \& Teed, M. (2017). Employer safety obligations, transformational leadership and their interactive effects on employee safety performance. Safety Science, 91, 405-412.

Neal, A., \& Griffin, M. A. (2002). Safety Climate and Safety Behaviour. Australian Journal of Management, 27(1_suppl), 67-75.

O'Toole, M. (2002). The relationship between employees' perceptions of safety and organizational culture. Journal of Safety Research, 33(2), 231-243.

Ocak, S., Köseoglu, M. A., \& Bertsch, A. (2015). Linkages among organizational culture, knowledge management, and patient safety performance: Evidence from a state hospital in a developing country. International Journal of Management and Enterprise Development, 14(1), 11-35.

Pater, R. (2001). Leadership Skills for the 21st Century.

Punnett, L., Cherniack, M., Henning, R., Morse, T., \& Faghri, P. (2013). Association of Schools of Public Health Workplace Occupational Framework Health Promotion Ergonomics for Integrating and.

Shang, K. C., \& Lu, C. S. (2009). Effects of safety climate on perceptions of safety performance in container terminal operations. Transport Reviews, 29(1), 1-19.

Shang, K. C., Yang, C. S., \& Lu, C. S. (2011). The effect of safety management on perceived safety performance in container stevedoring operations. International Journal of Shipping and Transport Logistics, 3(3), 323-341.

Teo, E. A. L., \& Feng, Y. (2011). The indirect effect of safety investment on safety performance for building projects. Architectural Science Review, 54(1), 65-80.

Ünal, Ö., Akbolat, M., Amarat, M., \& Tilkilioğlu, S. (2019). The role of the human factor in occupational safety and health performance. International Journal of Occupational Safety and Ergonomics, 0(0), 1-17.

Vinodkumar, M. N., \& Bhasi, M. (2010). Safety management practices and safety behavior: Assessing the mediating role of safety knowledge and motivation. Accident Analysis and Prevention, 42(6), 20822093.

Vredenburgh, A. G. (2002). Organizational safety. Journal of Safety Research, 33(2), 259-276.

$\mathrm{Wu}$, T.-C. (2005). The validity and reliability of safety leadership scale in Universities of Taiwan. International Journal of Technology and Engineering Education, 2(1), 27-42.

Wu, T. C., Chang, S. H., Shu, C. M., Chen, C. T., \& Wang, C. P. (2011). Safety leadership and safety performance in petrochemical industries: The mediating role of safety climate. Journal of Loss Prevention in the Process Industries, 24(6), 716-721.

Wu, T. C., Chen, C. H., \& Li, C. C. (2008). A correlation among safety leadership, safety climate, and safety performance. Journal of Loss Prevention in the Process Industries, 21(3), 307-318.

Zohar, D. (1980). Safety climate in industrial organizations: Theoretical and applied implications. Journal of Applied Psychology, 65(1), 96-102. 